\begin{tabular}{|l|l|l|l|l|l|}
\hline J. Tek. Ling & Vol. 10 & No. 2 & Hal. 161 - 166 & Jakarta, Mei 2009 & ISSN 1441-318X \\
\hline
\end{tabular}

\title{
KEANEKARAGAMAN JENIS-JENIS KAYU BAKAR DI DESA LAMPEAPI, PULAU WAWONII, SULAWESI TENGGARA
}

\author{
Siti Sunarti dan Rugayah \\ Peneliti di Pusat Penelitian Biologi \\ Lembaga IImu Pengetahuan Indonesia
}

\begin{abstract}
Fire wood is become one of the alternatif fuel to replace kerosene and gas. Because of the government regulation that replace kerosene into elpiji gas, many local people become prefer using fire wood for their cooking, although it cause air pollution. Twenty six plant species have been recorded as fire wood in Lampeapi, Wawonii Island, S.E. Sulawesi. Those species collected from the beach and also hill forest.
\end{abstract}

Keywords: Lampeapi, Wawonii, Sulawesi, forest, fire wood

\section{PENDAHULUAN}

\subsection{Latar Belakang}

Tumbuhan mempunyai banyak sekali manfaat salah satunya adalah sebagai kayu bakar atau sering disebut juga dengan kayu api. Kayu bakar merupakan salah satu bahan bakar alternatif sebagai pengganti minyak tanah dan gas. Secara ekonomi, menggunakan jenis bahan bakar alternatif lebih menguntungkan, hanya saja ketika melakukan kegiatan memasak timbul polusi asap yang bisa mengganggu lingkungan.

Dengan adanya kebijakan pemerintah yang mengganti minyak tanah ke elpiji membuat masyarakat resah dan semakin menderita terutama di perkotaan diseluruh Indonesia karena minyak tanah menjadi semakin langka, sementara harga gas elpiji semakin melonjak. Akibatnya untuk mengatasi hal tersebut maka banyak warga masyarakat beralih menggunakan kayu bakar untuk memasak, karena lebih murah. Lain halnya dengan di daerah yang jauh dari perkotaan dampaknya menjadi kurang terasa dibanding di perkotaan, mereka sudah terbiasa menggunakan kayu bakar untuk kegiatan sehari-hari. Mereka memanfaatkan tetumbuhan di sekitar tempat tinggalnya untuk dijadikan kayu bakar meskipun tetap membutuhkan minyak untuk hal-hal lainnya seperti untuk penerangan.

Berikut ini akan dilaporkan hasil penelitian tentang keanekaragaman jenisjenis kayu bakar didesa Lampeapi sebagai bahan bakar oleh masyarakat setempat.

\subsection{Tujuan Penelitian}

Tujuan penelitian ini adalah untuk mengetahui jenis-jenis tumbuhan apa saja yang dijadikan sebagai kayu bakar dan hasilnya diharapkan dapat menambah daftar baru tentang jenis-jenis tumbuhan penghasil bahan bakar alternatif. Di samping itu juga mengumpulkan spesimen bukti berupa koleksi spesimen herbarium untuk disimpan di Herbarium Bogoriense. 


\section{METODOLOGI}

\subsection{Lokasi Penelitian}

Keadaan umum lokasi penelitian desa Lampeapi secara administrasi termasuk dalam Kecamatan Wawonii Tengah (Pulau Wawonii), Kabupaten Konawe, Propinsi Sulawesi Tenggara. Desa ini dapat dicapai dengan menggunakan kapal kayu atau ferri dari ibu kota Propinsi Sulawesi Tenggara (Kendari) ke desa Lampeapi atau ke desa Langara terlebih dahulu, baru kemudian dilanjutkan menggunakan ojek ke desa Lampeapi. Desa Lampeapi terletak pada ketinggian 10-150 m dpl. , disebelah utara berbatasan dengan desa Lamong Opa, sebelah selatan dengan desa Wungkolo, sebelah barat dengan selat Wawonii dan di sebelah timur dengan kecamatan Wawonii Timur.
Mata pencaharian utama penduduk adalah bertani di ladang berpindah yang ditanami padi ladang, palawija dan sayuran serta berkebun.

Hutan Lampeapi jaraknya sekitar 7 $\mathrm{km}$ sebelah utara desa Lampeapi dan ke arah dalam sekitar 1-2 km sebelah timur dari jalan ke arah Langara - Lampeapi. Ketinggian tempatnya sekitar $60 \mathrm{~m}$ sampai dengan $290 \mathrm{~m}$ dari permukaan laut. Topografinya relatif datar dan sedikit bergelombang. Kondisi hutannya masih cukup baik, hal ini disebabkan karena penduduk setempat hanya memanfaatkan hutan untuk kepentingan mereka pribadii). Selama pengambilan kayu di hutan hanya untuk memenuhi kebutuhan mereka dan tidak untuk diperdagangkan tidak akan banyak berpengaruh pada komposisi dan struktur hutannya ${ }^{1}$. Hutan ini didominasi oleh Vatica umbonata Hook. f. Burck, Artocarpus

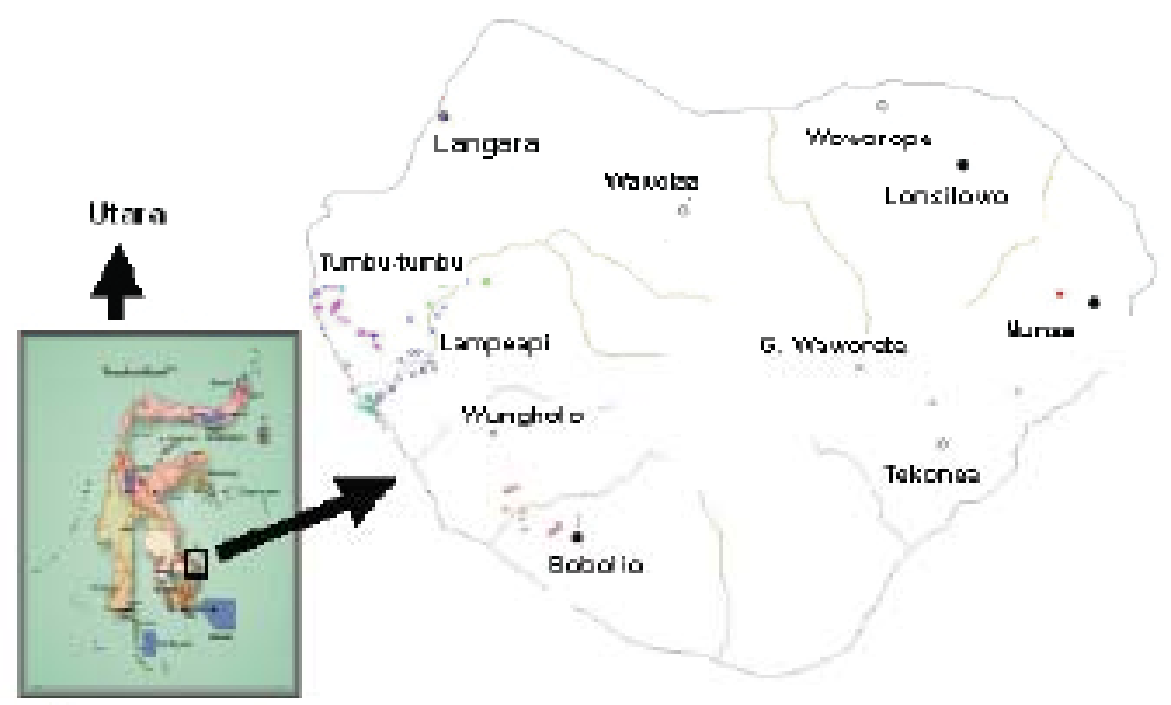

Desa Lampeapi terbagi atas 3 dusun dan dihuni oleh 200 kepala keluarga (KK). Letak pemukiman penduduk ke 3 dusun tersebut terkonsentrasi di sepanjang jalan utama desa. Penduduk sebagian besar etnik asli (suku Wawonii 90 \%) dan suku pendatang dari Bugis, Flores dan Jawa. Mayoritas penduduk beragama Islam. heterophyllus Lmk., Colona javanica (BI.) Burr., Castanopsis buruana Miq., Homalium foetidum dan Palaquium dasyphyllum Pierre $^{1)}$. Hutan yang masih bagus a.l. di perbukitan Puungkikima, Tontorala, Watunohu, Puuwulu, Lewelewembia, Langkororo, Larongkowea dan desa Wungkolo. 


\subsection{Cara Kerja}

Koleksi dilakukan terhadap semua tumbuhan yang dimanfaatkan sebagai kayu bakar, baik yang sedang berbunga atau berbuah maupun yang steril untuk dibuat herbariumnya. Data yang perlu dicatat antara lain ciri morfologi, lokasi, tanggal koleksi, nama daerah. Pemrosesan spesimen dengan melakukan pengeringan, pengidentifikasian, pembuatan label, penempelan, pemrosesan dalam data base, preservasi dan kemudian penyimpanan ke dalam koleksi. Pengidentifikasian dilakukan dengan mencocokkan spesimen tersebut dengan spesimen herbarium yang telah teridentifikasi, serta menggunakan buku flora antara lain: Flora of Java ${ }^{2,3}$ ) dan checklist of woody plants of Sulawesi, Indonesia4). Informasi pemanfaatan tumbuhan selain diperoleh dari data primer yaitu dengan mewawancarai masyarakat lokal yang berdomisili di sekitar hutan (merangkap sebagai pembantu lapangan), juga diperoleh dari data sekunder yaitu dari pustaka.

\section{HASIL DAN PEMBAHASAN}

\subsection{Keanekaragaman jenis tumbuhan sebagai kayu bakar}

Dari hasil penelitian dan penelusuran pustaka seluruhnya ada sekitar 24 jenis tumbuhan yang diperoleh di desa Lampeapi dan sekitarnya yang bermanfaat sebagai kayu bakar (Tabel 1). Tidak semua spesimen yang dikumpulkan dapat teridentifikasi sampai jenis karena spesimen bukti tersebut dalam keadaan steril, demikian pula informasi berat jenis dan kualitas kayunya belum semua jenis ada. Sumber kayu bakar dari hutan sekitar pantai dijumpai 9 jenis ${ }^{5)}$ yang semuanya merupakan jenis penyusun hutan mangrove. Menurut Prawiroatmodjo \& Sunardi $(2004)^{6}$ ) walaupun hutan mangrove di Lampeapi pada umumnya sudah mengalami gangguan terutama yang dekat dengan pemukiman, karena banyak yang ditebangi untuk keperluan kayu bakar dan rencana pembuatan empang/tambak akan tetapi kondisi hutannya masih cukup bagus karena regenerasi alaminya berjalan dengan baik. Sedangkan yang berasal dari hutan perbukitan ada 15 jenis, 12 jenis diantaranya biasa digunakan oleh penduduk dan yang tiga jenis yaitu "Keu waroko" (Geunsia ? pentandra Merr.), "Bayur" (Pterospermum celebicum Miq.), dan "Keu watu" (Homalium foetidum (Roxb.) Benth.) merupakan jenis-jenis yang manfaat utamanya untuk kayu balok dan sampan akan tetapi sering digunakan sebagai kayu bakar. Di daerah hutan perbukitan, pada umumnya jenis-jenis kayu bakar ini banyak dijumpai di wilayah hutan Puungkikima dan hutan Watunohu pada ketinggian $90-160 \mathrm{~m}$ dpl.

\subsection{Penggunaan kayu bakar}

Kayu bakar merupakan sumber energi yang mudah diperoleh, murah dan mudah terjangkau oleh masyarakat kalangan ekonomi lemah serta merupakan sumber daya yang dapat diperbaharui ${ }^{8}$. Nilai kalor dan berat jenis kayu dapat memberi petunjuk bahwa semua jenis kayu kurang dikenal dapat digunakan sebagai sumber energi7). Penggunaan jenis kayu sebagai sumber energi, pada umumnya lebih disukai jenis kayu yang berat jenisnya tinggi ${ }^{7}$. Walaupun semua jenis kayu dapat digunakan sebagai kayu bakar, namun penduduk di desadesa terpencil, terutama di pulau-pulau kecil seperti P. Wawonii kayu bakar yang digunakan penduduk masih sangat selektif dibandingkan dengan yang di pulau Jawa. Dari Tabel 1 terlihat bahwa hampir semua kayu bakar yang digunakan oleh penduduk di desa Lampeapi mempunyai berat jenis diatas 0.60 , berarti termasuk jenis kayu bakar yang kualitas kayunya baik. Hanya ada beberapa jenis yang mempunyai berat jenis dibawah 0.60 antara lain Callophyllum soulattri Burm. f., Geunsia pentandra Merr. dan Pterospermum celebicum Miq. serta ada beberapa jenis yang belum diketahui berat jenisnya. 
Tabel 1. Daftar jenis tumbuhan yang digunakan untuk kayu bakar di Lampeapi

\begin{tabular}{|c|l|l|l|c|c|c|}
\hline No & \multicolumn{2}{|c|}{ Nama Jenis } & \multicolumn{1}{c|}{ Nama Suku } & Nama Daerah & BJ & $\begin{array}{c}\text { Kualitas } \\
\text { kayu }\end{array}$ \\
\hline \multicolumn{7}{|c|}{ A. Jenis-jenis kayu bakar yang berasal dari hutan sekitar pantai } \\
\hline 1 & Bruguiera gymnorrhiza Lamk. & Rhizophoraceace & Tongke & 0.94 & K I \\
\hline 2 & $\begin{array}{l}\text { B. parviflora (Roxb.) Wight \& } \\
\text { Arnott. ex Griffith }\end{array}$ & Rhizophoraceace & Kukuni & & \\
\hline 3 & $\begin{array}{l}\text { Ceriops tagal (Perr.) C.B. } \\
\text { Robinson }\end{array}$ & Rhizophoraceace & Bulu & 0.97 & K I \\
\hline 4 & Excoecaria agallocha L. & Euphorbiaceae & & & \\
\hline 5 & Metrosideros sp. ? petiolata Kds. & Myrtaceae & Lara & 1.15 & K I \\
\hline 6 & Rhizophora mucronata Lmk & Rhizophoraceae & Tongke & & \\
\hline 7 & Rhizophora sp. & Rhizophoraceae & Tongke & & \\
\hline 8 & Sonneratia alba J.E. Smith & Sonneratiaceae & Padada & 0.78 & K II \\
\hline 9 & $\begin{array}{l}\text { Dolichandrone spathacea (L.f.) } \\
\text { K. Sch. }\end{array}$ & Bignoniaceae & Keu ule & & \\
\hline
\end{tabular}

\begin{tabular}{|c|l|l|l|l|l|}
\hline \multicolumn{7}{|c|}{ B. Jenis-jenis kayu bakar yang berasal dari hutan perbukitan } \\
\hline 10 & Carallia brachiata Merr. & Rhizophoraceae & Bakala & 0.82 & K II \\
\hline 11 & Casearia sp. & Flacourtiaceae & Keuwatu putih & & \\
\hline 12 & Cinnamomum sp. & Lauraceae & Kikir & & \\
\hline 13 & Callophyllum soulattri Burm.f. & Clusiaceae & Bitai & 0.54 & K IV \\
\hline 14 & Cratoxyllon celebicum BI. & Hypericaceae & Sisio & 0.63 & K III \\
\hline 15 & Celtis philippensis Blanco & Ulmaceae & Morohuka & 0.82 & K II \\
\hline 16 & $\begin{array}{l}\text { Erythroxylum cuneatum (Miq.) } \\
\text { Kurz }\end{array}$ & Erytroxylaceae & & 0.85 & K II \\
\hline 17 & Geunsia ? pentandra Merr. & Verbenaceae & Kayu/keu woroko & 0.43 & K V \\
\hline 18 & $\begin{array}{l}\text { Homalium foetidum (Roxb.) } \\
\text { Benth. }\end{array}$ & Flacourtiaceae & Keuwatu & 0.91 & K I \\
\hline 19 & $\begin{array}{l}\text { Mallotus floribundus (Blume) Mull. } \\
\text { Arg./ }\end{array}$ & Euphorbiaceae & Totombe= Wowoula & & \\
\hline 20 & $\begin{array}{l}\text { Mallotus paniculatus (Lamk) Mull. } \\
\text { Arg. }\end{array}$ & Euphorbiaceae & Susuantomi & & \\
\hline 21 & Mischocarpus sundaicus Blume & Sapindaceae & Kandunga & & \\
\hline 22 & $\begin{array}{l}\text { Pometia pinnata J.R. Forster \& } \\
\text { J.G. Forster }\end{array}$ & Sapindaceae & Kase & 0.77 & K II \\
\hline 23 & Pterospermum celebicum Miq. & Fabaceae & Bayur & 0.52 & K IV \\
\hline 24 & $\begin{array}{l}\text { Kjellbergiodendon celebicum } \\
\text { Merr. }\end{array}$ & Myrtaceae & Tombe uwa & 0.94 & K I \\
\hline
\end{tabular}

Keterangan : $\quad \mathrm{BJ}=$ Berat Jenis; $\mathrm{K}$ I Kelas I, istimewa; $\mathrm{K}$ II = Kelas II, amat baik; $\mathrm{K}$ III = Kelas III, amat baik; K IV = Kelas IV, sedang; K V = Kelas V, Jelek (Sumber Oey Djoen Seng (1964) disitir dalam Syachri, 1987. 
Dari Tabel 2 pun dapat dilihat bahwa jumlah jenis kayu bakar yang digunakan oleh penduduk di daerah Lampeapi ( $P$. Wawonii) sangat sedikit jika dibandingkan di Daerah Aliran Sungai Cisadane dan di Pulau Nusakambangan serta di desa-desa di kawasan Gunung Halimun. Hasil tersebut menunjukkan bahwa mereka lebih selektif dalam memilih jenis yang dimanfaatkan.
Griffith) dan "padada" (Sonneratia alba J.E. Smith). Menurut masyarakat setempat kayu bakar dari tumbuhan bakau lebih keras (tidak cepat habis), bara yang dihasilkan cukup tinggi dan lokasi pengambilan lebih dekat dari pada ke hutan dataran/ perbukitan ${ }^{10)}$. Pernyataan ini juga didukung oleh Heyne (1987) ${ }^{12)}$ yang mengatakan bahwa $B$. gymnorrhyza merupakan salah

Tabel 2. Perbedaan jumlah jenis kayu bakar yang digunakan penduduk di Lampeapi, DAS Cisadane, di P. Nusakambangan serta di daerah G. Halimun.

\begin{tabular}{|l|c|l|}
\hline \multicolumn{1}{|c|}{ Lokasi } & $\begin{array}{c}\text { Jumlah jenis } \\
\text { kayu bakar }\end{array}$ & \multicolumn{1}{|c|}{ Sumber } \\
\hline Lampeapi (P. Wawoni) & 24 & Sunarti \& Rugayah/data prima \\
\hline DAS Cisadane & 55 & Susiarti, 1991 ${ }^{\text {9) }}$ \\
\hline P. Nusakambangan & 45 & Setyowati \& Rahayu, 2005 ${ }^{10)}$ \\
\hline Ciptarasa (G. Halimun, Jabar) & 229 & Harada dkk, 2001 ${ }^{11)}$ \\
\hline Leuwijamang (G. Halimun, Jabar) & 202 & Harada, 2001 ${ }^{11)}$ \\
\hline Cibedug (G. Halimun, Jabar) & 68 & Harada dkk, 2001 $^{11)}$ \\
\hline
\end{tabular}

Menurut informasi penduduk setempat, mereka akan mencari kayu bakar yang bagus dengan kriteria antara lain kayunya cepat menyala walaupun masih basah, asapnya tidak terlalu banyak, dan tahan lama. Kayu bakar yang diambil umumnya berasal dari tegakan hutan yang masih hidup atau dari sisa-sisa penebangan kayu untuk pembuatan sampan, di kebun-kebun serta pekarangan. Kalau hanya sekedar pengambilan kayu di hutan untuk keperluan kayu bakar tidak terlalu mengkhawatirkan atau membahayakan akan tetapi kalau ditebang untuk keperluan pemesanan sampan maka akan mengancam kelestarian tumbuhan yang ada di hutan ini. Oleh karena itu perlu pengawasan dari aparat pemerintah.

Penduduk lokal di desa Lampeapi yang tempat tinggalnya lebih dekat ke pantai, mereka lebih menyukai menggunakan kayu bakar dari jenis-jenis tumbuhan hutan bakau seperti "tongke" (Rhyzophora mucronata Lmk, Bruguiera gymnorrhyza Lmk), "kukuni" (B. parviflora (roxb.) Wight \& Arnott ex satu jenis kayu bakar yang terbaik, karena kayunya walaupun baru ditebang atau dalam keadaan basah akan cepat menyala. Demikian pula Rhyzophora mucronata Lmk, Cratoxyllum celebicum Bl., Mischocarpus sundaicus Blume, Soneratia alba J.E. Smith, Pometia pinnata J.R. Forster \& J.G Forster kayunya menghasilkan arang dan kayu bakar yang berkualitas baik ${ }^{12,13)}$. Untuk menjaga kelestarian habitat tumbuhan dan hutan maka perlu adanya penyuluhan antara lain konservasi, budidaya tumbuhan, teknologi paska panen dan lain-lain.

\section{KESIMPULAN}

Dari hasil penelitian ini diperoleh 24 jenis tumbuhan yang benar-benar manfaat utamanya sebagai kayu bakar. Sumber kayu bakar yang dipakai oleh penduduk di desa Lampeapi ada yang berasal dari hutan pantai (9 jenis) dan hutan pegunungan (15 jenis). Jumlah jenis tersebut lebih sedikit dibandingkan dengan yang dimanfaatkan di Jawa. 


\section{DAFTAR PUSTAKA}

1. Rahajoe, J.S., E. Mirmanto dan Ismail. 2004. Pengelompokan Jenis Tumbuhan Berdasarkan Kandungan Hara dan Teksture Tanah di Hutan Dataran Rendah Desa Lampeapi, P. Wawonii, Sulawesi Tenggara. Dalam Laporan Teknik 2004. Proyek Inventarisasi dan Karakterisasi Sumber Daya Hayati. PUSLIT BIOLOGI -LIPI. Hal 87 - 102.

2. Backer, C.A. dan R.J. Bakh. v/d Brink Jr. 1963. Flora of Java vol.1 Groningen: N.V.P. Noordhooff.

3. Backer, C.A. dan R.J. Bakh. v/d Brink Jr. 1963. Flora of Java vol.2 Groningen: N.V.P. Noordhooff.

4. Keâler, P.J.A. , M.M. Bos, Daza, S.E.C.S., Kop, A., L.P.M. Willemse, R. Pitopang, and S.R. Gradstein. 2002. Checklist of woody plants of Sulawesi, Indonesia. Blumea Supplement 14: $1-160$

5. Rahayu, M., S. Prawiroatmodjo dan Sunardi. 2004. Kajian Pemanfaatan Tumbuhan oleh Masyarakat di Kecamatan Wawonii, Sulawesi Tenggara. Dalam Laporan Teknik 2004. Pusat Penelitian dan Pengembangan Biologi - LIPI. Hal 57 - 70

6. Prawiroatmodjo, S dan Sunardi. 2004. Kajian Pemanfaatan Tumbuhan oleh Masyarakat di Kecamatan Wawonii, Sulawesi Tenggara. Dalam Laporan Teknik 2004. Pusat Penelitian dan Pengembangan Biologi - LIPI. Hal $71-85$

7. Syachri, T.N. 1987. Pemanfaatan Kayu Kurang Dikenal Sebagai Sumber Energi. Makalah yang disampaikan dalam Diskusi Pemanfaatan Kayu Kurang Dikenal. Badan Penelitian dan Pengembangan Kehutan. Bogor, 13 - 14 Januari 1987.
8. Anonimous. 1983. Bagaimana Mendapat Kayu Bakar Di Daerah Kritis. Bulletin Informasi Pertanian. Ujung Pandang: 4 - 20

9. Susiarti, S. 1991. Telaah Konsumsi Kayu Bakar Untuk Kebutuhan Rumah Tangga di Sub DAS Ciapus DAS Hulu Cisadane. Prosiding Seminar Hasil Penelitian dan Pengembangan Sumber Daya Hayati 1990/1991. Pusat Penelitian dan Pengembangan Biologi - LIPI. Bogor 15 Mei 1991. Hal. $91-96$

10. Setyowati, F.M. dan M. Rahayu. 2005. Keanekaragaman dan Pemanfaatan Tumbuhan di Pulau Nusakambangan - Cilacap, Jawa Tengah. J. Tek. Ling. P3TL-BPPT. 6 (1): 291 - 302

11. Harada, K. , A. Muzakkir, M. Rahayu and Widada. 2001. Traditional people and biodiversity conservation in Gunung Halimun National Park. Research and Conservation of Biodiversity in Indonesia. Vol. VII. Biodiversity Conservation Project. JICA. Bogor.

12. Heyne, K. 1987. Tumbuhan Berguna Indonesia (Terjemahan). Badan Penelitian dan Pengembangan Kehutanan. Jakarta.

13. de Graaf, N.R., J.W. Hildebrand, P.B. Laming and J.M. Fundter. 1994. Pometia J.R. Forster \& J.G. Forster. In Soerianegara, I. \& R.H.M.J. Lemmens (Edits). In Timber Trees: Major commercial timbers. Plant Resources of South-East Asia 5 (1): 357 - 362. 